Research Article

\title{
Cardiovascular Safety of Clonidine and Dexmedetomidine in Critically Ill Patients after Cardiac Surgery
}

\author{
Angelina Grest, Judith Kurmann, Markus Müller, Victor Jeger, Bernard Krüger, \\ Donat R. Spahn $\mathbb{D}$, Dominique Bettex $\mathbb{D}$, and Alain Rudiger $\mathbb{D}$
}

Institute for Anaesthesiology, University Zurich and University Hospital Zurich, Zürich, Switzerland

Correspondence should be addressed to Alain Rudiger; alain.rudiger@spital-limmattal.ch

Received 15 September 2019; Accepted 26 February 2020; Published 7 May 2020

Academic Editor: Loek P.H. Leenen

Copyright (c) 2020 Angelina Grest et al. This is an open access article distributed under the Creative Commons Attribution License, which permits unrestricted use, distribution, and reproduction in any medium, provided the original work is properly cited.

\begin{abstract}
Purpose. The aim of this retrospective study was to assess the haemodynamic adverse effects of clonidine and dexmedetomidine in critically ill patients after cardiac surgery. Methods. 2769 patients were screened during the 30-month study period. Heart rate (HR), mean arterial pressure (MAP), and norepinephrine requirements were assessed 3-hourly during the first 12 hours of the continuous drug infusion. Results are given as median (interquartile range) or numbers (percentages). Results. Patients receiving clonidine ( $n=193)$ were younger (66 (57-73) vs $70(63-77)$ years, $p=0.003)$ and had a lower SAPS II (35 (27-48) vs 41 (31-54), $p=0.008)$ compared with patients receiving dexmedetomidine $(n=141)$. At the start of the drug infusion, HR (90 (75-100) vs 90 $(80-105) \mathrm{bpm}, p=0.028)$, MAP $(70(65-80)$ vs $70(65-75) \mathrm{mmHg}, p=0.093)$, and norepinephrine $(0.05(0.00-0.11)$ vs 0.12 $(0.03-0.19) \mathrm{mcg} / \mathrm{kg} / \mathrm{min}, p<0.001)$ were recorded in patients with clonidine and dexmedetomidine. Bradycardia $(\mathrm{HR}<60 \mathrm{bpm})$ developed in $7.8 \%$ with clonidine and $5.7 \%$ with dexmedetomidine $(p=0.51)$. Between baseline and 12 hours, norepinephrine remained stable in the clonidine group $(0.00(-0.04-0.02) \mathrm{mcg} / \mathrm{kg} / \mathrm{min})$ and decreased in the dexmedetomidine group $(-0.03$ $(-0.10-0.02) \mathrm{mcg} / \mathrm{kg} / \mathrm{min}, p=0.007)$. Conclusions. Dexmedetomidine and the low-cost drug clonidine can both be used safely in selected patients after cardiac surgery.
\end{abstract}

\section{Introduction}

Maintaining an optimal level of comfort and safety for critically ill patients is a universal goal in postoperative care $[1,2]$. This can be achieved with the use of alpha- 2 adrenergic agents, in particular, clonidine and dexmedetomidine, which induce dose-dependent sedation, analgesia, and anxiolysis $[3,4]$. Clonidine has traditionally been used in our institution for sedation in the perioperative setting and in critically ill patients after cardiac surgery [5-9]. Particular benefits of this sedative are its low acquisition costs. Adverse effects of clonidine are hypotension and bradycardia [10], which might limit its use in haemodynamic unstable patients.

In 2013, dexmedetomidine was introduced into the Swiss market. The number of reports describing the benefits of dexmedetomidine is growing continuously since then: dexmedetomidine reduced the lengths of mechanical ventilation and hospital stay, and it lowered the overall costs compared with that of propofol [11-13]. The perioperative use of dexmedetomidine was associated with a decreased incidence of postoperative complications, delirium, and mortality up to one year after cardiac surgery [14]. However, dexmedetomidine treatment is expensive and might not be universally available.

To date, there is a shortage of studies comparing dexmedetomidine and clonidine in the intensive care unit (ICU) setting. The only direct comparison between the two alpha-2 agonists available is limited by the low number of included patients ( $n=35$ per group) [15].

\section{Materials and Methods}

2.1. Objectives. The aim of this study was to assess the haemodynamic adverse effects of the alpha- 2 agonists clonidine and dexmedetomidine in critically ill patients after cardiac surgery. 
2.2. Design. The study is a retrospective observational study. The study protocol was approved by the ethics council of the Canton of Zurich, Switzerland (BASEC-Nr. PB_201600333). Patients' general consent was required for the screening of their charts and the retrospective analysis of their data.

2.3. Setting. The study was performed in the cardiosurgical ICU at the University Hospital Zurich, Switzerland. The treatment principles of patients hospitalized in this particular ICU have been summarized $[16,17]$. In our practice, patients generally arrive from the operation room under propofol sedation. Alpha-2 agonists are second-line agents when prolonged sedation becomes necessary. In our clinical practice, clonidine is used in haemodynamically stable patients with norepinephrine requirements $<0.1 \mathrm{mcg} / \mathrm{kg} / \mathrm{min}$, while dexmedetomidine is used in patients with a norepinephrine requirement $<0.3 \mathrm{mcg} / \mathrm{kg} / \mathrm{min}$. The patients requiring higher norepinephrine support are usually sedated with midazolam. However, no strict sedation guidelines were applied during the study period, and the choice of sedative was at the discretion of the ICU consultant on call.

2.4. Data Collection. Demographic and baseline characteristics including the Simplified Acute Physiology Score (SAPS) II were collected for both groups. Higher SAPS values indicate more severe illness and a higher predicted mortality [18]. Medical information and laboratory data were extracted from the electronic patient information system. Medication and haemodynamic variables were collected from the handwritten patients' charts.

2.5. Population. All patients admitted to our cardiovascular ICU during an 18-month-period were screened for treatment with either clonidine (Catapresan ${ }^{\circledR}$ ) and/or dexmedetomidine (Dexdor $\left.{ }^{\circledR}\right)$. Study inclusion criteria for patients were treatment with either clonidine or dexmedetomidine. The exclusion criteria were absence of consent for screening, treatment with both clonidine and dexmedetomidine during the same ICU stay, only drug bolus administration in absence of a continuous drug infusion, absence of cardiac surgery, use of either extracorporeal life support, or ventricular assist devices. Patients were included in the analysis only once. Those receiving both clonidine and dexmedetomidine during the same ICU stay were not considered for this comparison.

2.6. Variables. Heart rate, mean arterial pressure, and norepinephrine requirements were recorded 3-hourly. The observation period started with the beginning of the alpha-2 agonist infusion and ended 12-hours later. Bradycardia was defined as a decrease of the heart rate below 60 beats per minute.

2.7. Study Size. The study size was defined by the 30 -month screening period (convenience sample).
2.8. Statistics. Median (interquartile range) and numbers (percentages) were calculated for the overall sample and subgroups. Missing values were replaced by the last recorded value (carrying forward). Comparisons were made with the use of the Mann-Whitney $U$ test, Fisher's exact test, or the chi-squared test, as appropriate. The null hypothesis was rejected with a two-sided $p$ value $<0.05$. All analyses were performed with the use of SPSS 24 for Windows 10 .

\section{Results}

During the 30-month study period, 2769 patients were admitted to the cardiosurgical ICU. A summary of included and excluded patients is given in Figure 1. Eventually, this study compared 193 patients sedated with clonidine and 141 patients sedated with dexmedetomidine. Patient characteristics are displayed in Table 1.

All patients underwent cardiac surgery, which included valve surgery in 179 (54\%), coronary artery bypass surgery in $137(41 \%)$, aortic dissection surgery in 35 (10.5\%), aortic aneurysm surgery in 50 (15\%), other major vascular surgery in $25(7.5 \%)$, myocardial resection in $5(1.5 \%)$, implantable cardioverter defibrillator implantation in 12 (3.6\%), and heart transplantation in $9(2.7 \%)$ patients. Several patients received combinations of the above-listed interventions. Cardiopulmonary bypass was required in 251 (75\%) of the operations without significant difference between the two patient groups $(p=0.31)$. The postoperative left ventricular ejection fraction in both groups was 55 (45-60)\%; $p=0.16$.

The average initial dose of clonidine was 0.38 $(0.29-0.50) \mathrm{mcg} / \mathrm{kg} / \mathrm{h}$. The average initial dexmedetomidine dose was $0.80(0.61-1.12) \mathrm{mcg} / \mathrm{kg} / \mathrm{h}$. Both drugs were started on ICU day $2(1-3) ; p=0.18$. Patients were treated with clonidine for a total duration of 16 (11-50) hours. In the dexmedetomidine group, patients received the drug infusion for a total duration of 31 (13-68) hours. Study drug doses over time are displayed in Figure 2.

Haemodynamic variables, laboratory values, and ICU management at the start of clonidine or dexmedetomidine treatment are shown in Table 2. As shown in Figure 3(a), the median arterial pressure remained stable in both groups during the twelve-hour observation period. Heart rate decreased in both groups by $-10(-20-0)$ bpm $(p=0.33)$, Figure $3(\mathrm{~b})$. Bradycardia developed in $7.8 \%$ of the patients treated with clonidine and $5.7 \%$ of patients treated with dexmedetomidine $(p=0.52)$. At the beginning of the alpa-2 agonist infusion, norepinephrine requirements were higher in patients receiving dexmedetomidine $(0.05(0.00-0.11)$ vs $0.12(0.03-0.19) \mathrm{mcg} / \mathrm{kg} / \mathrm{min}, p<0.001)$. Between baseline and the twelve-hour follow-up, the norepinephrine requirements remained stable in the clonidine group $(0.00$ $(-0.04-0.02) \mathrm{mcg} / \mathrm{kg} / \mathrm{min})$, whereas a decrease of norepinephrine was seen in the dexmedetomidine group $(-0.03$ $(-0.10-0.02) \mathrm{mcg} / \mathrm{kg} / \mathrm{min}, p=0.007$ ) (Figure 3(c)). During the 12-hour observation period, a transient increase in norepinephrine was recorded in 95 (49\%) patients treated with clonidine and 60 (43\%) patients treated with dexmedetomidine $(p=0.27)$ by $0.04 \quad(0.03-0.08)$ and 0.06 $(0.03-0.12) \mathrm{mcg} / \mathrm{kg} / \mathrm{min}(p=0.014)$, respectively. 


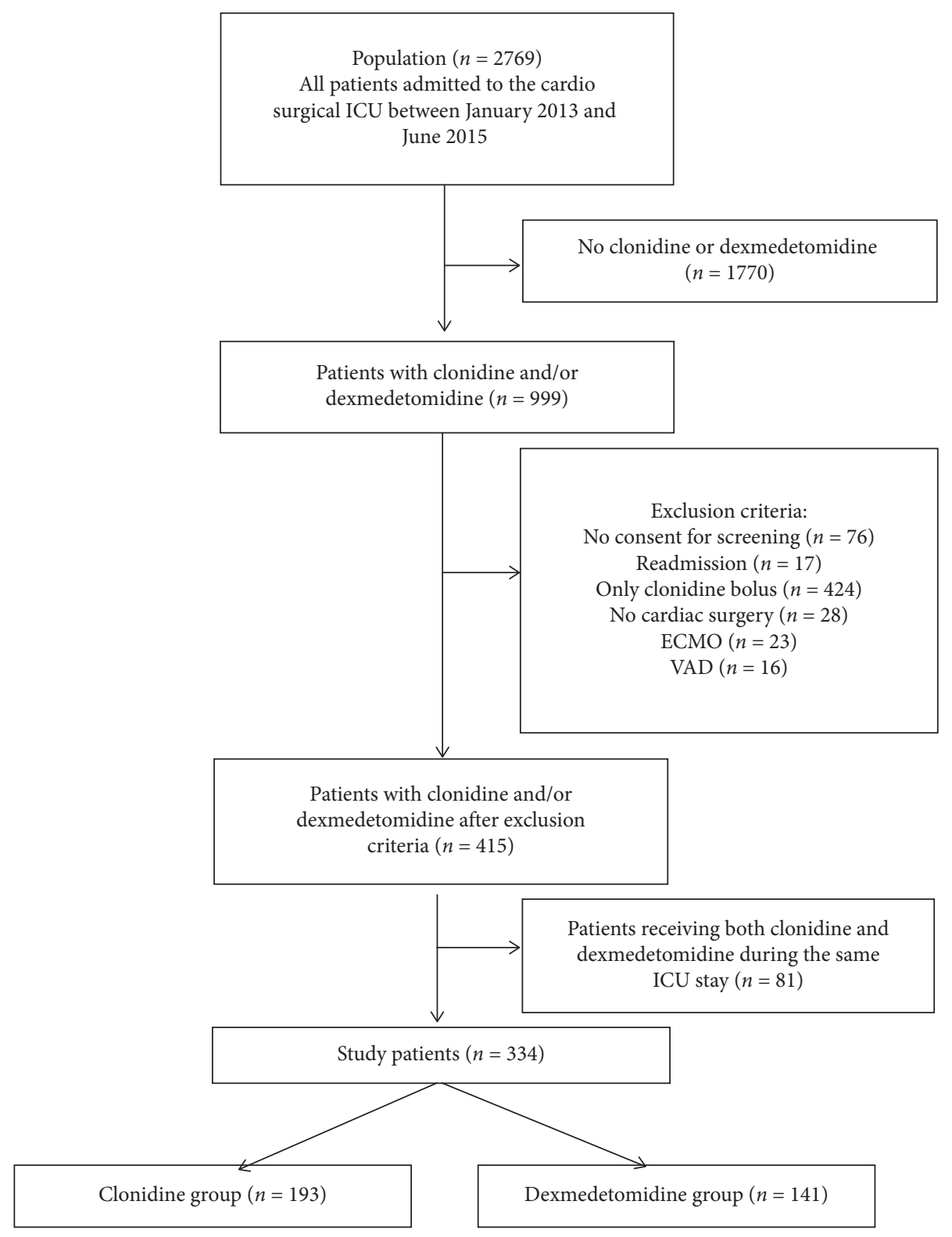

FIGURE 1: Study population with inclusion and exclusion criteria. ECMO: extracorporeal membrane oxygenation; VAD: ventricular assist device; ICU: intensive care unit.

TABLE 1: Patient characteristics.

\begin{tabular}{|c|c|c|c|c|}
\hline Variable & All $(n=334)$ & Clonidine group $(n=193)$ & Dexmedetomidine group $(n=141)$ & $p$ value \\
\hline Age (years) & $68(58-75)$ & $66(57-73)$ & $70(63-77)$ & 0.003 \\
\hline Male gender & $256(77 \%)$ & $145(75 \%)$ & $111(79 \%)$ & 0.513 \\
\hline Weight (kg) & $78(68-90)$ & $79(69-91)$ & $78(68-88)$ & 0.188 \\
\hline SAPS II (points) & $37(29-50)$ & $35(27-48)$ & $41(31-54)$ & 0.008 \\
\hline ICU length of stay (days) & $5(2-8)$ & $4(2-7)$ & $6(3-8)$ & 0.004 \\
\hline ICU mortality & $12(3.6 \%)$ & $7(3.6 \%)$ & $5(3.5 \%)$ & 1.000 \\
\hline
\end{tabular}

ICU: intensive care unit; SAPS: simplified acute physiology score.

\section{Discussion}

This retrospective analysis demonstrates that both clonidine and dexmedetomidine can be used safely for sedation of patients after cardiac surgery hospitalized in the ICU.
4.1. Population. Patients receiving dexmedetomidine were older and had a higher SAPS II score and a higher requirement for norepinephrine at the start of the drug infusion, indicating that these patients had a higher severity of illness than the patients treated with clonidine. This reflects 


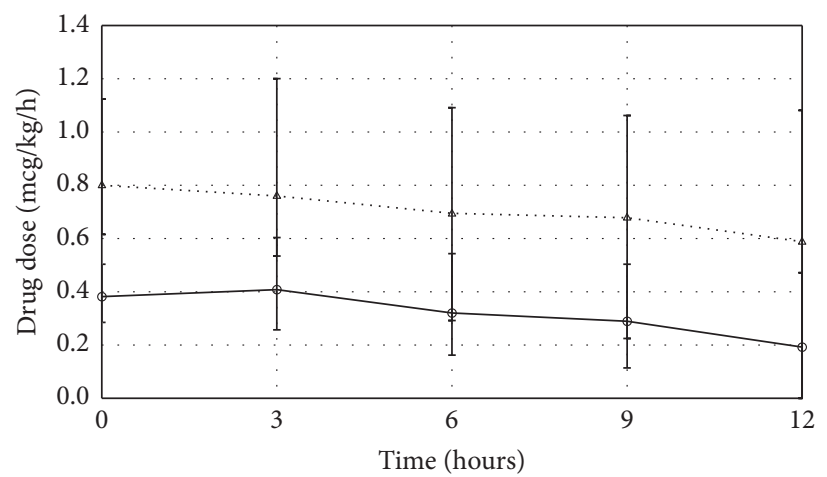

FIGURE 2: Drug dosages during dexmedetomidine and clonidine infusion. The clonidine and dexmedetomidine doses decreased by -0.14 $(-0.35-0.00) \mathrm{mcg} / \mathrm{kg} / \mathrm{h}$ and $-0.12(-0.69-0.21)$, respectively. Values indicate median \pm interquartile range. Solid line $(-)$ indicates clonidine patients; dashed line (- - ) indicates dexmedetomidine patients. Values represent median (interquartile range).

TABle 2: Physiological, laboratory, and treatment variables at the start of clonidine or dexmedetomidine therapy.

\begin{tabular}{|c|c|c|c|c|}
\hline Variable & All $(n=334)$ & Clonidine group $(n=193)$ & Dexmedetomidine group $(n=141)$ & $p$ value \\
\hline $\begin{array}{l}\text { Hemodynamic parameters } \\
\text { (i) Heart rate }(1 / \mathrm{min}) \\
\text { (ii) Mean arterial pressure }(\mathrm{mmHg}) \\
\text { (iii) Central venous pressure }(\mathrm{mmHg}) \\
\text { (iv) Cardiac index }(1 / \mathrm{m}[2] / \mathrm{min}) \\
\text { (v) } \mathrm{SvO}_{2}(\%)\end{array}$ & $\begin{array}{c}90(80-100) \\
70(65-75) n=333 \\
10(7-12) n=322 \\
2.7(2.5-3.3) n=51 \\
69(63-75) \quad n=239 \\
\end{array}$ & $\begin{array}{c}90(75-100) \\
70(65-80) n=192 \\
9(6-12) n=185 \\
2.6(2.4-3.0) n=19 \\
69(64-75) n=173 \\
\end{array}$ & $\begin{array}{c}90(80-105) \\
70(65-75) \\
10(8-13) n=137 \\
2.8(2.6-3.5) n=32 \\
65(59-75) n=66 \\
\end{array}$ & $\begin{array}{l}\mathbf{0 . 0 2 8} \\
0.093 \\
\mathbf{0 . 0 2 5} \\
0.101 \\
0.060 \\
\end{array}$ \\
\hline $\begin{array}{l}\text { Laboratory values } \\
\text { (i) Haemoglobin (g/l) } \\
\text { (ii) White blood cell count }(\mathrm{G} / \mathrm{l}) \\
\text { (iii) C-reactive protein }(\mathrm{mg} / \mathrm{l}) \\
\text { (iv) Procalcitonin }(\mathrm{mcg} / \mathrm{l}) \\
\text { (v) Creatinine }(\mathrm{mcmol} / \mathrm{l}) \\
\text { (vi) Aspartate transaminase }(\mathrm{U} / \mathrm{l}) \\
\text { (vii) Alanine transaminase }(\mathrm{U} / \mathrm{l}) \\
\text { (viii) Creatine kinase }(\mathrm{U} / \mathrm{l}) \\
\text { (ix) Myoglobin }(\mathrm{mcg} / \mathrm{l}) \\
\text { (x) Troponin }(\mathrm{mcg} / \mathrm{l}) \\
\text { (xi) Arterial lactate }(\mathrm{mmol} / \mathrm{l}) \\
\text { (xii) Arterial base excess (mmol/l) }\end{array}$ & $\begin{array}{c}91(83-103) n=331 \\
11.5(8.8-15.1) n=331 \\
62(14-131) n=326 \\
1.91(0.52-6.25) n=46 \\
99(78-141) \\
62(39-119) n=322 \\
27(17-58) n=325 \\
474(242-847) n=329 \\
371(218-767) n=325 \\
0.81(0.35-1.69) n=320 \\
1.5(1.0-2.3) n=330 \\
-1.1(-3.0-0.3) n=330\end{array}$ & $\begin{array}{c}94(85-107) \\
11.8(8.8-15.1) n=191 \\
53(6-133) n=185 \\
1.43(0.31-4.10) n=28 \\
94(76-133) \\
55(35-107) n=184 \\
27(16-58) n=188 \\
484(228-889) n=188 \\
378(229-670) n=186 \\
0.78(0.30-1.54) n=184 \\
1.4(1.05-2.2) \\
-1.2(-2.7-0.3)\end{array}$ & $\begin{array}{c}88(80-97) n=138 \\
11.1(8.6-15.1) n=140 \\
69(34-129) \\
3.46(1.10-17.07) n=18 \\
110(83-150) \\
71(44-133) n=138 \\
28(17-63) n=137 \\
468(255-807) n=141 \\
368(214-898) n=139 \\
0.84(0.43-1.97) n=136 \\
1.5(1.0-2.6) n=137 \\
-1.0(-3.3-0.4) n=137\end{array}$ & $\begin{array}{l}\mathbf{0 . 0 0 2} \\
0.498 \\
0.100 \\
0.075 \\
\mathbf{0 . 0 0 5} \\
\mathbf{0 . 0 2 6} \\
0.606 \\
0.919 \\
0.640 \\
0.135 \\
0.650 \\
0.574 \\
\end{array}$ \\
\hline $\begin{array}{l}\text { Treatments } \\
\text { Propofol } n(\%)\end{array}$ & $127(50 \%)$ & & J/ (40\%) & 0.494 \\
\hline $\begin{array}{l}\text { Mechanical ventilation } \\
\text { (i) Invasive } n(\%) \\
\text { (ii) Noninvasive } n(\%) \\
\text { Renal replacement therapy- } n(\%) \\
\text { Norepinephrine } n(\%)\end{array}$ & $\begin{array}{c}235(70 \%) \\
7(2.1 \%) \\
34(10.2 \%) \\
248(74 \%)\end{array}$ & $\begin{array}{c}124(64 \%) \\
5(2.6 \%) \\
23(12 \%) \\
133(69 \%)\end{array}$ & $\begin{array}{c}111(79 \%) \\
2(1.4 \%) \\
11(7.8 \%) \\
115(82 \%) \\
\end{array}$ & $\begin{array}{l}0.235 \\
\mathbf{0 . 0 1 1}\end{array}$ \\
\hline $\begin{array}{l}\text { Inotropes } \\
\text { (i) Milrinone } n(\%) \\
\text { (ii) Epinephrine } n(\%)\end{array}$ & $\begin{array}{l}80(24 \%) \\
73(22 \%)\end{array}$ & $\begin{array}{l}35(18 \%) \\
33(17 \%)\end{array}$ & & $\begin{array}{l}0.004 \\
0.016\end{array}$ \\
\hline
\end{tabular}

$\mathrm{SvO}_{2}$ : central venous oxygen saturation. Variables were collected at start of clonidine or dexmedetomidine treatment.

our clinical practice that clonidine is used in haemodynamically more stable patients. This translated in a longer ICU length of stay in the dexmedetomidine group, while mortality was low in both groups.

4.2. Clonidine. We used clonidine in a median dose of $0.4 \mathrm{mcg} / \mathrm{kg} / \mathrm{h}$, while Srivastava et al. used a mean dosage of $1.4 \mathrm{mcg} / \mathrm{kg} / \mathrm{h}$. Haemodynamic instability is one of the most frequently mentioned side-effects of clonidine [10].
Srivastava et al. described the frequencies for bradycardia (heart rate below $50 \mathrm{bpm}$ ) and hypotension (systolic blood pressure below $80 \mathrm{mmHg}$ or diastolic blood pressure below $50 \mathrm{mmHg}$ ) during clonidine infusion with $8.6 \%$ (3/35) and $31 \%(11 / 35)$, respectively [15]. In our ICU setting, the overall risk of bradycardia was below ten percent and mean arterial blood pressure remained stable due to adjustments of the norepinephrine doses. Overall, norepinephrine requirements did not increase during the 12-hour observation period. 


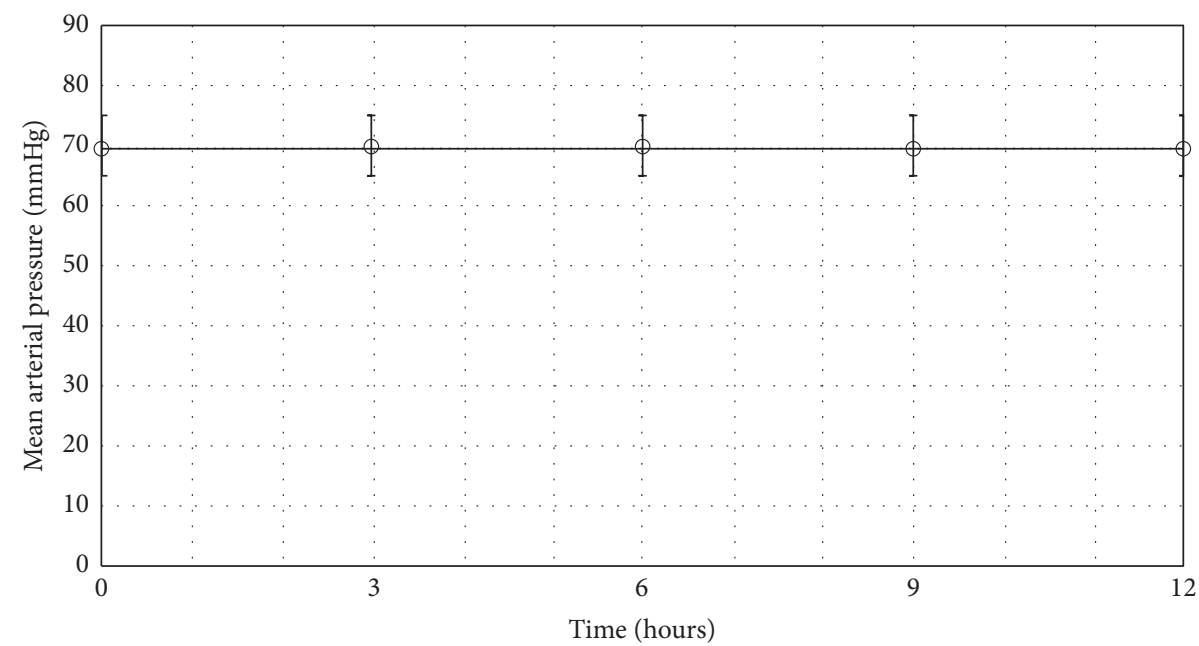

(a)

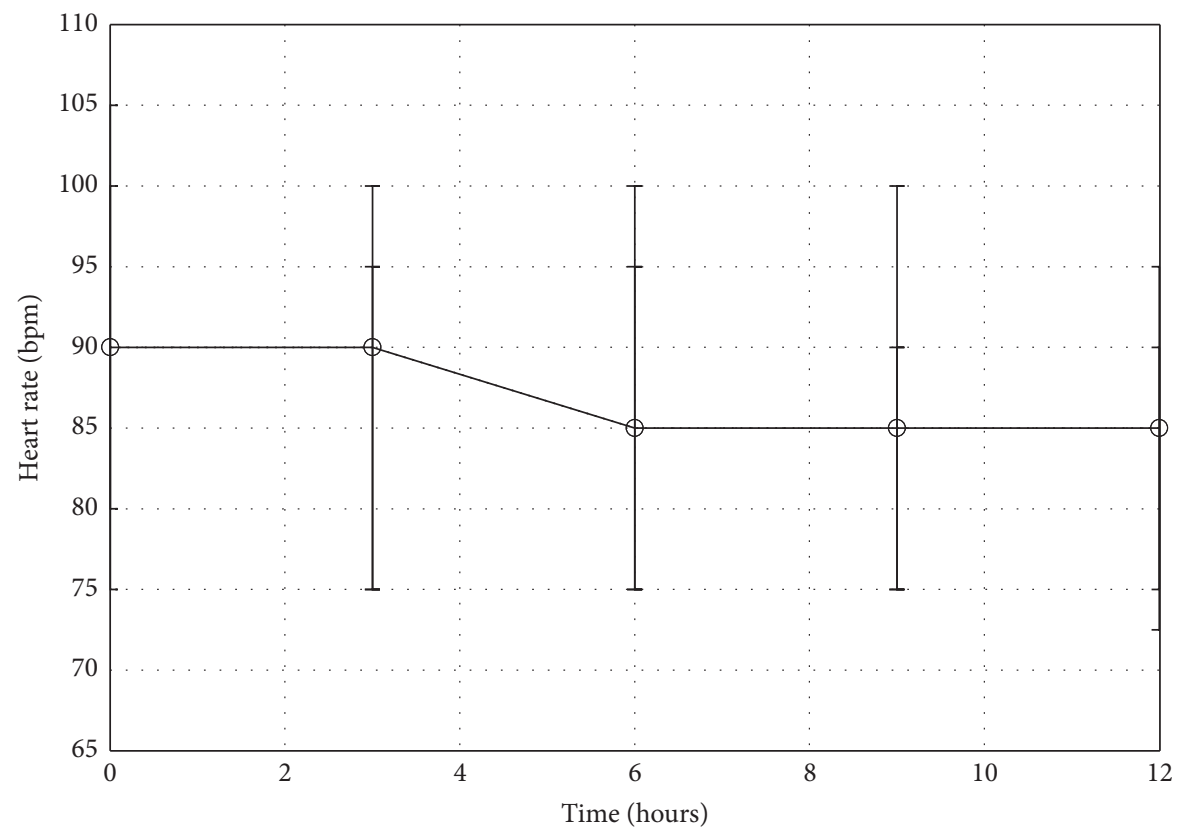

(b)

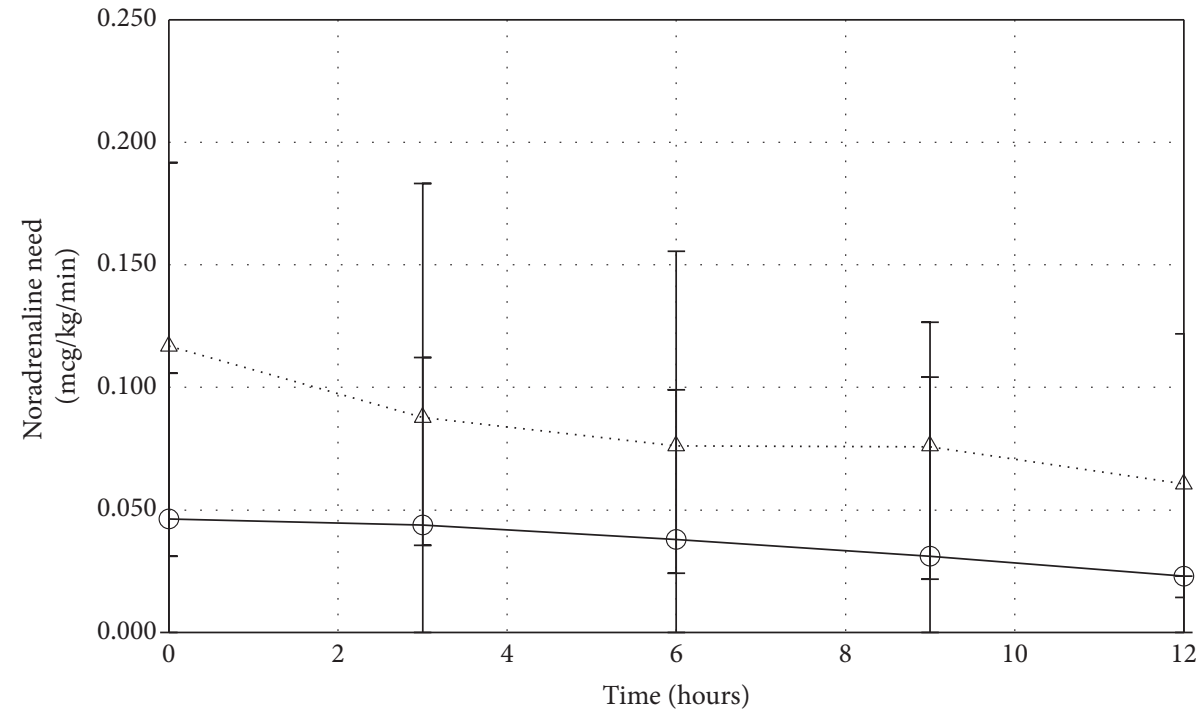

(c)

Figure 3: Hemodynamic variables during dexmedetomidine and clonidine infusion. Solid line (-) indicates clonidine patients; dashed line (- - ) indicates dexmedetomidine patients. Values represent median (interquartile range). 
The major advantages of clonidine are its low costs. A 24hour treatment of an average study patient (body weight $79 \mathrm{~kg}$, clonidine dose $0.4 \mathrm{mcg} / \mathrm{kg} / \mathrm{h}$ ) costs about 18 Euros. Based on our findings, we can recommend clonidine for sedation in ICU patients after cardiac surgery with norepinephrine requirements up to $0.1 \mathrm{mcg} / \mathrm{kg} / \mathrm{min}$ at the beginning of the clonidine infusion, provided the patients are adequately monitored and managed.

4.3. Dexmedetomidine. In the dexmedetomidine group, patients were treated with a median dose of $0.8 \mathrm{mcg} / \mathrm{kg} / \mathrm{h}$, while Srivastava et al. used a mean dose of only $0.4 \mathrm{mcg} / \mathrm{kg} / \mathrm{h}$. In the Midex and Prodex studies, the median dose of dexmedetomidine was 0.45 and $0.96 \mathrm{mcg} / \mathrm{kg} / \mathrm{h}$, respectively [19]. Hypotension (no definition provided) occurred in $21 \%$ $(51 / 247)$ in the Midex study and in $13 \%(32 / 246)$ in the Prodex study [19]. Srivastava et al. described the frequencies for bradycardia (heart rate below $50 \mathrm{bpm}$ ) and hypotension (systolic blood pressure below $80 \mathrm{mmHg}$ or diastolic blood pressure below $50 \mathrm{mmHg}$ ) during dexmedetomidine infusion with $11 \%(4 / 35)$ and $8.6 \%(3 / 35)$, respectively [15]. In our study, mean arterial blood pressure in the dexmedetomidine group remained stable over time. Less than half of the patients being treated with dexmedetomidine showed a transient increase of norepinephrine, while the overall norepinephrine need was decreasing during the observation period. This suggests that dexmedetomidine provides good haemodynamic stability.

In the Midex and Prodex studies, the risk of bradycardia (no definition provided) was $14.2 \%$ (35/247) and 13.0\% (32/ 246), respectively [19]. In our study, the incidence of bradycardia was $5.7 \%$ in the dexmedetomidine group.

Up to now, merely one existing study directly compared the two alpha- 2 agonists in the ICU setting. Srivastava's findings concerning the haemodynamic stability conform to our findings, namely, that dexmedetomidine showed a better haemodynamic stability than clonidine. However, due to distinctive drug dosages, it is not possible to make a proper comparison between the two studies: While we used twice as much dexmedetomidine, our clonidine infusion doses were lower by a factor of three. Additionally, Srivastava's study is limited by the small study group of 70 patients [15]. Recently, Morelli et al. investigated the effect of dexmedetomidine sedation on norepinephrine requirements in 38 septic shock patients in a crossover trial. Four hours after the stop of propofol and the initiation of a dexmedetomidine infusion of $0.7 \pm 0.2 \mathrm{mcg} / \mathrm{kg} / \mathrm{h}$, the norepinephrine dose decreased from $0.69 \pm 0.72 \mathrm{mcg} / \mathrm{kg} / \mathrm{min}$ to $0.30 \pm 0.25 \mu \cdot \mathrm{g} /$ $\mathrm{kg} / \mathrm{min}(p<0.005)$. Back on propofol 8 hours after stopping dexmedetomidine, norepinephrine increased again to $0.42 \pm 0.36 \mu \mathrm{g} / \mathrm{kg} / \mathrm{min} \quad(p<0.005)$ [20]. While the study population was different and the norepinephrine doses at baseline were much higher, the dexmedetomidine doses administered and the trend of the norepinephrine changes were similar, supporting in part the findings of the present study.

The costs for a 24-hour treatment of dexmedetomidine for an average study patient (body weight $78 \mathrm{~kg}$, dexmedetomidine dose $0.8 \mathrm{mcg} / \mathrm{kg} / \mathrm{h}$ ) are approximately 224 Euros. Hence, dexmedetomidine therapy is exceeding the costs of clonidine by more than ten times. While clonidine is a good choice for haemodynamically stable patients (NA $\leq 0.1 \mathrm{mcg} / \mathrm{kg} / \mathrm{min}$ ), our study results suggest that dexmedetomidine is a safe option for patients with a moderate haemodynamic instability (norepinephrine $>0.1$, but $\leq 0.2 \mathrm{mcg} / \mathrm{kg} / \mathrm{min}$ ). For highly unstable patients (norepinephrine $>0.2 \mathrm{mcg} / \mathrm{kg} / \mathrm{min}$ ), a treatment with another sedative (e.g., midazolam) may be considered.

Based on these data, prospective studies can be planned for a direct comparison between the two alpha-2 agonists, potentially also in patients with haemodynamic instability. More data regarding antidelirogenic effects and impact on length of mechanical ventilation or length of stay are needed for clonidine or dexmedetomidine treatments. As treatment with clonidine is inexpensive compared with dexmedetomidine, further research would be of economic interest for hospital administrators and public health.

4.4. Limitations. Our study has some important limitations. First, this study has a retrospective design, and the patients were not randomly allocated to a patient group. As a result, the two patient groups have different baseline characteristics, making a direct head-to-head comparison of the two drugs impossible. However, this study represents a real-life experience giving information on clinical practice in our institution.

Second, all study variables were assessed 3-hourly and reflect more the overall trend than short-term fluctuations. Hence, if the patients showed relevant changes between the assessment times, we might have missed those. Clearly, not every variable of the patient condition (e.g., altertness and pain) and ICU interventions (e.g., fluid administration, analgesics, and termination of propofol) that may affect blood pressure and heart rate was collected and analysed in this study. In addition, some patients in our ICU had transient epicardial pacemakers with the possibility of pacing for haemodynamic reasons. This may have had an impact on the incidence of bradycardia in our study. Nevertheless, our results reflect haemodynamic changes in critically ill patients after cardiac surgery treated with alpha2 agonists under every day conditions.

\section{Conclusions}

In patients treated with clonidine or dexmedetomidine, the incidence of bradycardia was below $10 \%$ and not different between groups. With clonidine, half of the patients required a mild increase in norepinephrine, while the overall norepinephrine use remained constant over 12 hours. With dexmedetomidine, less than half of the patients required a norepinephrine increase, while the overall norepinephrine use decreased during the observation period. This suggests that both dexmedetomidine and the lower-cost drug clonidine can be used safely for sedation in selected patients after cardiac surgery. 


\section{Abbreviations}

HR: Heart rate

ICU: Intensive care unit

MAP: Mean arterial pressure

SAPS: Simplified acute physiology score.

\section{Data Availability}

The data used to support this study are available from the corresponding author upon request.

\section{Additional Points}

To date, there is a shortage of studies comparing the cardiovascular safety of dexmedetomidine and clonidine in the intensive care unit setting. This retrospective study assesses the hemodynamic adverse effects of clonidine and dexmedetomidine in critically ill patients after cardiac surgery. Between baseline and 12 hours, norepinephrine requirements remained stable in the clonidine group and decreased in the dexmedetomidine group. Bradycardia $(\mathrm{HR}<60 \mathrm{bpm})$ developed in less than $10 \%$ of patients with no difference between groups. Dexmedetomidine and the low-cost drug clonidine can both be used safely in selected patients after cardiac surgery.

\section{Disclosure}

Parts of the results were presented as oral presentation at the annual conference of the Swiss Society of Intensive Care Medicine. During the last 5 years, VJ, BK, DB, and AR have received lecture fees and travel expenses from Orion, the manufacturer of dexmedetomidine, for their talks on levosimendan.

\section{Conflicts of Interest}

The authors declare that there are no conflicts of interest regarding the publication of this paper.

\section{Acknowledgments}

The authors thank the interdisciplinary, multiprofessional team of the cardiosurgical ICU at the University Hospital Zurich for their high-quality care of their patients. The study has been supported by the departmental funds.

\section{References}

[1] J. Jacobi, G. L. Fraser, D. B. Coursin et al., "Clinical practice guidelines for the sustained use of sedatives and analgesics in the critically ill adult," Critical Care Medicine, vol. 30, no. 1, pp. 119-141, 2002.

[2] J. Barr, G. L. Fraser, K. Puntillo et al., "Clinical practice guidelines for the management of pain, agitation, and delirium in adult patients in the intensive care unit," Critical Care Medicine, vol. 41, no. 1, pp. 263-306, 2013.

[3] K. Chen, Z. Lu, Y. C. Xin, Y. Cai, Y. Chen, and S. M. Pan, "Alpha-2 agonists for long-term sedation during mechanical ventilation in critically ill patients," Cochrane Database of Systematic Reviews, vol. 1, 2015.

[4] M. Cruickshank, L. Henderson, G. MacLennan et al., "Alpha2 agonists for sedation of mechanically ventilated adults in intensive care units: a systematic review," Health Technology Assessment, vol. 20, no. 25, pp. 1-118, 2016.

[5] S. B. Fehr, M. P. Zalunardo, B. Seifert et al., "Clonidine decreases propofol requirements during anaesthesia: effect on bispectral index," British Journal of Anaesthesia, vol. 86, no. 5, pp. 627-632, 2001.

[6] M. T. Ganter, C. K. Hofer, D. R. Spahn et al., "The effect of clonidine on perioperative blood coagulation," Journal of Clinical Anesthesia, vol. 17, no. 6, pp. 456-462, 2005.

[7] M. P. Zalunardo, D. Serafino, P. Szelloe et al., "Preoperative clonidine blunts hyperadrenergic and hyperdynamic responses to prolonged tourniquet pressure during general anesthesia," Anesthesia \& Analgesia, vol. 94, no. 3, pp. 615-618, 2002.

[8] M. P. Zalunardo, A. Zollinger, D. R. Spahn, B. Seifert, and T. Pasch, "Preoperative clonidine attenuates stress response during emergence from anesthesia," Journal of Clinical Anesthesia, vol. 12, no. 5, pp. 343-349, 2000.

[9] M. P. Zalunardo, A. Zollinger, D. R. Spahn et al., "Effects of intravenous and oral clonidine on hemodynamic and plasmacatecholamine response due to endotracheal intubation," Journal of Clinical Anesthesia, vol. 9, no. 2, pp. 143-147, 1997.

[10] J. W. Devlin, S. Mallow-Corbett, and R. R. Riker, “Adverse drug events associated with the use of analgesics, sedatives, and antipsychotics in the intensive care unit," Critical Care Medicine, vol. 38, pp. S231-S243, 2010.

[11] M. C. Reade, G. M. Eastwood, R. Bellomo et al., "Effect of dexmedetomidine added to standard care on ventilator-free time in patients with agitated delirium: a randomized clinical trial," JAMA, vol. 315, no. 14, pp. 1460-1468, 2016.

[12] J. A. Curtis, M. K. Hollinger, and H. B. Jain, "Propofol-based versus dexmedetomidine-based sedation in cardiac surgery patients," Journal of Cardiothoracic and Vascular Anesthesia, vol. 27, no. 6, pp. 1289-1294, 2013.

[13] B. N. Thoma, J. Li, C. M. McDaniel, C. J. Wordell, N. Cavarocchi, and L. T. Pizzi, "Clinical and economic impact of substituting dexmedetomidine for propofol due to a US drug shortage: examination of coronary artery bypass graft patients at an urban medical centre," PharmacoEconomics, vol. 32, no. 2, pp. 149-157, 2014.

[14] F. Ji, Z. Li, H. Nguyen et al., "Perioperative dexmedetomidine improves outcomes of cardiac surgery," Circulation, vol. 127, no. 15, pp. 1576-1584, 2013.

[15] U. Srivastava, M. E. Sarkar, A. Kumar et al., "Comparison of clonidine and dexmedetomidine for short-term sedation of intensive care unit patients," Indian Journal of Critical Care Medicine: Peer-Reviewed, Official Publication of Indian Society of Critical Care Medicine, vol. 18, no. 18, pp. 431-436, 2014.

[16] T. Hauffe, B. Krüger, D. Bettex et al., "Shock management for cardio-surgical ICU patients-the golden hours," Cardiac Failure Review, vol. 1, no. 2, pp. 75-82, 2015.

[17] T. Hauffe, B. Krüger, D. Bettex et al., "Shock management for cardio-surgical intensive care unit patient: the silver days," Cardiac Failure Review, vol. 2, no. 1, pp. 56-62, 2016.

[18] A. Granholm, M. H. Møller, M. Krag, A. Perner, and P. B. Hjortrup, "Predictive performance of the simplified acute physiology score (SAPS) II and the initial sequential organ failure assessment (SOFA) score in acutely ill intensive care patients: post-hoc analyses of the SUP-ICU inception cohort study," PLoS One, vol. 11, Article ID e0168948, 2016. 
[19] S. M. Jakob, E. Ruokonen, R. M. Grounds et al., "Dexmedetomidine vs midazolam or propofol for sedation during prolonged mechanical ventilation: two randomized controlled trials," JAMA, vol. 307, no. 11, pp. 1151-1160, 2012.

[20] A. Morelli, F. Sanfilippo, P. Arnemann et al., "The effect of propofol and dexmedetomidine sedation on norepinephrine requirements in septic shock patients," Critical Care Medicine, vol. 47, no. 2, pp. e89-e95, 2019. 